\title{
Object-oriented classification for land cover of North Thang Long Industrial area using Worldview-2 data
}

\author{
Ha Thu Thi Le ${ }^{1,}{ }^{*}$, Long Van Hoang ${ }^{2}$, Trung Van Nguyen ${ }^{1}$ \\ ${ }^{1}$ Hanoi University of Mining and Geology, Hanoi, Vietnam \\ ${ }^{2}$ Loc Ninh land registration office, Binh Phuoc, Vietnam
}

\begin{tabular}{l} 
ARTICLE INFO \\
\hline Article history: \\
Received 25th Sept. 2020 \\
Revised 25 $5^{\text {th }}$ Dec. 2020 \\
Accepted 26 $6^{\text {th }}$ Jan. 2021 \\
\hline Keywords: \\
Industrial area, \\
Land cover, \\
Object - oriented classification, \\
Worldview-2.
\end{tabular}

\section{ABSTRACT}

Land cover/land use classification using high spatial resolution remote sensing data has difficulty in distinguishing object classes from different spectral values based on structures, shapes, and spatial elements. This paper focuses on the object - oriented classification method to extract artificial surfaces at Thang Long industrial area by Worldview-2 data with a spatial resolution of $1.8 \mathrm{~m}$. Extraction of 05 types of land cover/land use using object-oriented classification method based on reflectance spectral characteristics, shape index, object location, brightness, NDVI index, and object density gained high-quality classification results. The overall accuracy of classification results for land cover/land use of Thang Long industrial area is about 0.85 and Kappa index is about 0.81 .

${ }^{*}$ Corresponding author

E-mail: lethithuha@humg.edu.vn

DOI: 10.46326/JMES.2021.62(1).02 


\title{
Phân loại lớp phủ bề mặt khu công nghiệp Bắc Thăng Long bằng phương pháp phân loại hướng đối tượng sử dụng dữ liệu ảnh vệ tinh độ phân giải cao Worldview-2
}

\author{
Lê Thi Thu Hà ${ }^{1,}{ }^{*}$, Hoàng Văn Long ${ }^{2}$, Nguyễn Văn Trung ${ }^{1}$ \\ ${ }^{1}$ Trường Đại học Mỏ - Địa chất, Hà Nội, Việt Nam \\ ${ }^{2}$ Chi nhánh Văn phòng Đăng ký đất đai huyện Lộc Ninh, Bình Phước, Việt Nam
}

THÔNG TIN BÀI BÁO T TÓM TẮT

Quá trình:

Nhận bài 25/9/2020

Sứa xong 25/12/2020

Chap nhận đăng 26/01/2021

Tù̀ khóa:

Khu công nghiệp,

Lớp phủ bề mặt,

Phương pháp phân loại

hướng đối tượng,

Ảnh vệ tinh Worldview-2.
Phân loại lóp phủ/sử dụng đất bằng ảnh vệ tinh độ phân giải cao thường gặp phái khó khăn là do sự phức tạp của bề mặt đất, nhất là đối với các khu vực đô thị. Mỗi pixel trên ảnh có thể chứa nhiều đối tượng khác nhau, hoặc bi ảnh hưởng bởi bóng của cây và các công trình xây dựng. Bài báo này sử dung phương pháp phân loai hướng đối tương trong viềc phân loai lớp phủ nhân tạo ở khu công nghiệp sử dụng tư liệu ảnh Worldview-2 có độ phân giải không gian 1,8 m. Việc chiết tách các loại hình lớp phủ/sử dụng đất dựa vào việc phân cấp các đối tương theo đặc trưng phổ phản xạ, chỉ số hình dạng, vi trí các đối tượng, độ sáng, chỉ số thực vật NDVI và mật độ các đối tượng mang lai hiêu quả cao về chất lương kết quả phân loai. Kết quả phân loại lớp phủ/sử dụng đất ở khu công nghiệp Bắc Thăng Long tù̀ dữ liệu ảnh vệ tinh độ phân giải cao Worldview-2 đạt được độ chính xác cao được thể hiện qua sai số toàn bộ $(0,85)$ và chỉ số Kappa $(0,81)$.

C 2021 Trường Đại học Mỏ - Địa chất. Tất cả các quyền được bảo đảm.

\section{Mở đầu}

Trong những năm gần đây, với những tiến bộ trong công nghệ thu thập dữ liệu viễn thám và nhu cầu ngày càng tăng về các ứng dụng viễn thám, dữ liệu viễn thám có độ phân giải không gian cao đang dần trở nên phổ biến hơn (Belward và Skøien, 2015). Các loại dữ liệu viễn thám vệ tinh có độ phân giải không gian cao, bao gồm: Worldview, Ikonos, SuperView, Gaofen và dữ liệu ảnh máy bay không người lái (UAV). Với khả năng tiếp cận của

*Tác giả liên hệ

E - mail: lethithuha@humg.edu.vn DOI: 10.46326/JMES.2021.62(1).02 một lượng lớn dữ liệu viễn thám có độ phân giải cao đã tạo ra một thách thức cho việc phân loại ảnh viễn thám (Desheng Liu và Fanxia, 2010). Hiện nay, phương pháp phân loại ảnh có thể được gộp thành các nhóm: có kiểm định và không kiểm định; hoặc thống kê và phi thống kê; hoặc cứng và mềm (fuzzy); hoặc pixel, dưới pixel, hiện chỉnh bản đồ và phân loại định hướng đối tượng (Mario 2009; Choodarathnakara va nnk 2012). Trong đó, phương pháp phân loại hướng đối tượng thường được áp dụng với ảnh vệ tinh có độ phân giải không gian cao (Benz và nnk., 2015) với các ưu điểm: (a) - việc thay đổi các đơn vị phân loại từ pixel thành các đối tượng hình ảnh sẽ làm giảm sự biến đổi quang phổ bên trong lớp và loại bỏ được 
hiệu ứng muối tiêu trong kết quả phân loại dựa trên pixel; (b) - một tập hợp lớn các tính năng đặc trưng cho các thuộc tính không gian, cấu trúc và ngữ cảnh của đối tượng có thể được lấy làm thông tin bổ sung cho các quan sát quang phổ trực tiếp để có khả năng cải thiện độ chính xác của kết quả phân loại (Guo và nnk., 2007).

Cảnh quan đô thị thường là một tổ hợp phức tạp của các tòa nhà, đường xá, bãi đậu xe, vỉa hè, sân vườn, nghĩa trang, đất, nước, khu công nghiệp,... Mỗi bề mặt thành phần đô thị sở hữu các đặc tính lý sinh độc đáo và liên quan đến môi trường xung quanh của chúng để tạo ra sự phức tạp về không gian của các hệ thống sinh thái đô thị và các mô hình cảnh quan (Qihao Weng, 2020). Để thực hiện việc chiết tách các lớp phủ nhân tạo và các lớp phủ bề mặt khác, các đặc trưng phổ của các đối tượng lớp phủ bề mặt trên các kênh phổ cần được khảo sát sự khác nhau nhằm chiết tách các lớp phủ đảm bảo độ chính xác theo yêu cầu. Nghiên cứu của Kamal và nnk. (2015) đã tiến hành đo phản xạ phổ của các đối tượng lớp phủ bề mặt khu vực đô thị trên tất cả các kênh của dữ liệu Worldview-2 phục vụ việc phân loại các đối tượng ở khu vực đô thị. Bên cạnh đó, các dữ liệu ảnh vệ tinh có nhiều kênh phổ cũng giúp tách biệt được các đối tượng lớp phủ mà mắt thường có thể nhầm lẫn khi giải đoán do khả năng phân biệt phổ của các đối tượng lớp phủ tự nhiên hoặc nhân tạo.

Trong nghiên cứu này, nhóm tác giả sử dụng phương pháp phân loại hướng đối tượng cho ảnh vệ tinh Worldview-2 với 8 kênh phổ để phân loại cho các đối tượng lớp phủ nhân tạo và tự nhiên ở khu vực khu công nghiệp Bắc Thăng Long, Hà Nội. Mục đích là sử dụng kết hợp các điều kiện phân loại về đặc trưng phổ của các đối tượng lớp phủ nhân tạo ở các kênh khác nhau để tách các lớp phủ đó một cách tường minh nhất.

\section{Khu vực nghiên cứu và dữ liệu sử dụng}

Khu công nghiệp Bắc Thăng Long nằm ở phía Bắc của sông Hồng cách trung tâm Thành phố Hà Nội khoảng $10 \mathrm{~km}$. Vị trí địa lý của khu vực nghiên cứu trong khoảng từ $21006^{\prime}$ đến $21^{00} 08^{\prime}$ vĩ độ bắc và từ 106045'đến 106048' kinh độ đông (Hình 1).

Dữ liệu sử dụng là ảnh Worldview-2 được thu nhận ngày 28 tháng 9 năm 2018 ở mức độ xử lý 2A với hệ tọa độ UTM, WGS84-48N. Ảnh được nắn chỉnh hình học theo bản đồ địa hình và đưa về hệ quy chiếu VN2000.

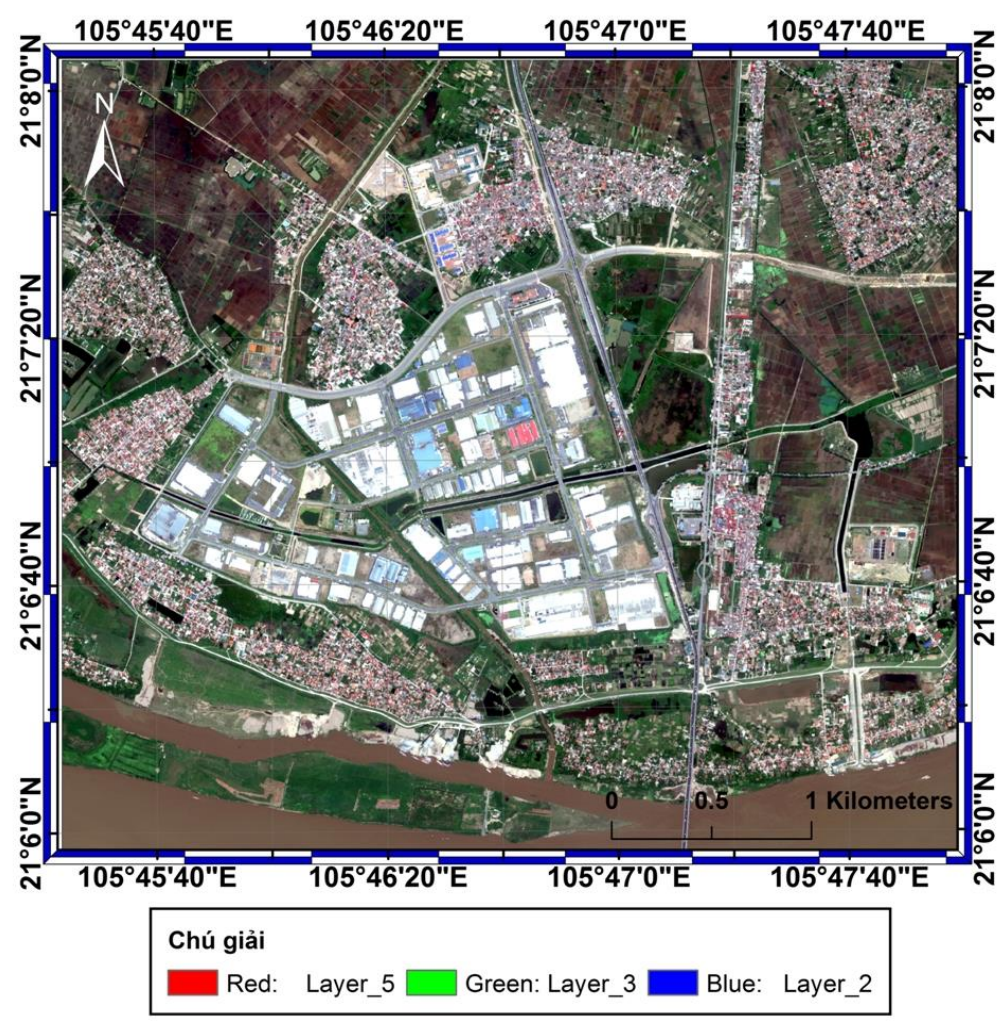

Hình 1. Khu công nghiệp Bắc Thăng Long. 
Dũ̃ liệu Worldview-2 bao gồm 8 kênh đa phổ và 1 kênh toàn sắc như Hình 2 . Để tăng cường khả năng phân biệt phản xạ phổ giữa các đối tượng lớp phủ tự nhiên và nhân tạo đối với dữ liệu ảnh vệ tinh độ phân giải không gian cao, một số kênh phổ được bổ sung thêm bao gồm kênh coastal, kênh vàng (yellow), kênh gần đỏ (Red Edge) và 2 kênh gần hồng ngoại NIR1 và NIR2. Dữ liệu Worldview2 có độ phân giải không gian $1,8 \mathrm{~m}$ và $0,46 \mathrm{~m}$ (kích thước pixel tương ứng trên thực địa) lần lượt đối với 8 kênh đa phổ và kênh toàn sắc.

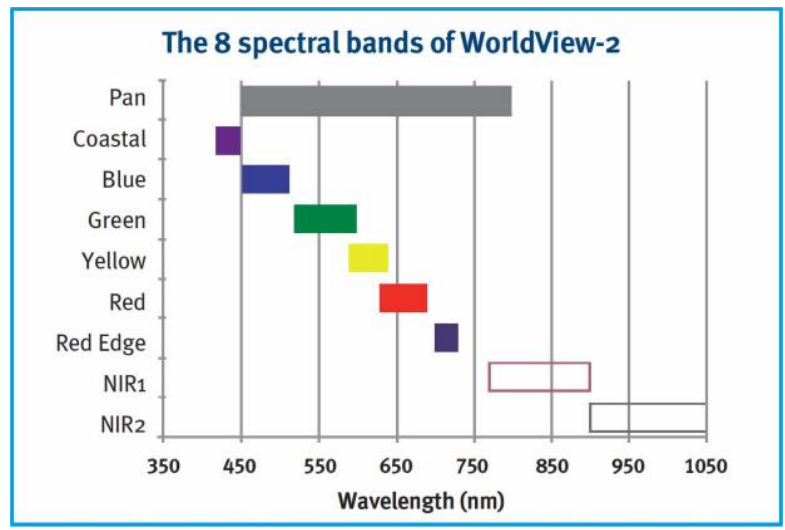

Hình 2. Các kênh phổ của dũ liệu Worldview-2 (Digitalglobal, 2009).

\section{Phương pháp nghiên cứu}

\subsection{Phản xạ phổ của lópp phủ bề mặt trên các kênh ảnh vệ tinh Worldview-2}

Nghiên cứu của Kamal và nnk. (2015) đã tiến hành thu thập các thông tin lớp phủ bề mặt ở thực địa và đo các giá trị phổ trên ảnh vệ tinh Worldview-2 biểu thị trên Hình 2 .

Các đối tượng tự nhiên bao gồm nước mặt, các loại lớp phủ thực vật, đất khô đều theo đúng qui luật về các đặc trưng phản xạ phổ. Tuy nhiên, các đối tượng lớp phủ nhân tạo có phản xạ phổ khác biệt như đường nhựa, đất bùn và đặc biệt là mái nhà có phản xạ phổ giảm dần đối với các kênh phổ có bước sóng dài hơn.

\subsection{Phương pháp phân loại định hướng đối turong}

Quy trình của phân loại hướng đối tượng được chia thành các bước như sau:

- Phân mảnh đa độ phân giải,

- Xác định các lớp phủ bề mặt cần phân loại,

- Phân loại theo cây quyết định (qui tắc cho phân loại),

- Đánh giá kết quả phân loại.
Phân loại hướng đối tượng được thực hiện trên phần mềm eCognition (Baatz và nnk., 2004) đã được mô tả bởi (Whiteside và Ahmad, 2004). Quá trình này được chia thành 2 bước bao gồm phân mảnh và phân loại.

\subsubsection{Phân mảnh đa độ phân giải}

Công đoạn đầu tiên của phương pháp phân loại hướng đối tượng là phân mảnh ảnh thành các đối tượng theo hai mức tỷ lệ. Ảnh cắt theo ranh giới khu vực nghiên cứu được phân mảnh thành các đối tượng bằng phần mềm eCognition. Sự phân mảnh ảnh thành các đối tượng chịu ảnh hưởng của ba thông số: tỷ lệ (scale), màu sắc (colour) và độ chặt (compactness) (Willhauck và nnk., 2000). Thông số tỷ lệ ảnh hưởng trực tiếp đến kích thước của đối tượng sẽ được phân mảnh. Thông số màu sắc liên quan đến hình dạng và cấu trúc của đặc thù riêng của các đối tượng. Lựa chọn thông số tối ưu sẽ giúp cho các đối tượng được phân mảnh đồng nhất về phổ hoặc không gian. Trong khi đó, độ chặt được định nghĩa là tỷ số giữa chu vi của một đối tượng và căn bậc hai của tổng số pixel nằm trong đối tượng đó.

Thông số tỷ lệ được đặt bởi người xử lý ảnh chịu ảnh hưởng bởi sự đồng nhất của các điểm ảnh (pixel) trong mỗi đối tượng. Thông số màu sắc cân bằng sự đồng nhất về màu sắc và đồng nhất về hình dạng. Thông số độ chặt cân bằng giữa phân bố ít và phân bố nhiều. Trọng số của các thông số này là một tiêu chuẩn đồng nhất trong mỗi đối tượng. Kiểm tra trực quan các đối tượng từ kết quả thay đổi trọng số được sử dụng để xác định giá trị toàn bộ đối với trọng số ở mỗi mức tỷ lệ (Bảng 1). Đầu tiên, sự đồng nhất của các điểm ảnh được xem xét đối với các đối tượng của mỗi lớp phủ thực vật. Dựa vào mô hình số độ cao và mực nước, hai nhóm được chia ra là vùng cao và vùng thấp tương ứng với thực vật, thực vật ngập lụt và bề mặt nước với hai mức tỷ lệ được chọn cho quá trình phân loại. Lựa chọn tốt nhất đối với thông số tỷ lệ lần lượt là 5 và 10 cho mức 1 và 2 (Kavzoglu, 2014). Thông số độ chặt được cố định ở 0,5, các thông số hình dạng khác nhau được kiểm tra có giả trị từ $0,1 \div 0,9$. Độ chính xác cao nhất của phân loại nhận được trong nghiên cứu tương ứng với thông số hình dạng lần lượt là 0,2 và 0,4 đối với mức tỷ lệ 1 và 2 . Tiếp tục giữ thông số tỷ lệ và hình dạng, giá trị tối ưu nhất đối với thông số độ chặt là 0,7 . 
Bảng 1. Các giá trị đối với thông số trọng số ở mỗi mức tỷ lẹ.

\begin{tabular}{|c|c|c|c|}
\hline $\begin{array}{c}\text { Mức tỷ } \\
\text { lệ }\end{array}$ & $\begin{array}{c}\text { Thông số } \\
\text { tỷ lệ }\end{array}$ & $\begin{array}{c}\text { Thông số } \\
\text { hình dạng }\end{array}$ & $\begin{array}{c}\text { Thông số } \\
\text { độ chặt }\end{array}$ \\
\hline 1 & 5 & 0,2 & 0,7 \\
\hline 2 & 10 & 0,4 & 0,7 \\
\hline
\end{tabular}

\subsubsection{Phân loại ảnh}

Phân loại hướng đối tượng khác với phân loại có giám định về phương pháp lấy mẫu và xây dựng lý thuyết cơ sở. Quy trình của phân loại hướng đối tượng là theo các lớp thứ bậc. Dựa vào cấu trúc thứ bậc, các lớp được nhóm theo phương pháp này cho phép đi xuống theo sự mô tả của lớp thấp hơn. Phân nhóm theo cấu trúc thứ bậc mở ra một phạm vi lớn đối với việc xây dựng các định nghĩa về ảnh và đối với các chiến lược phân tích khác nhau. Tương tác của nguời dùng với quy trình dựa vào thống kê, cấu trúc, hình dạng và mối quan hệ giữa các đối tượng được định nghĩa như vùng mẫu. Sự phân loại của một đối tượng có theo phương pháp người láng giềng gần nhất "phân loại cứng" hoặc "phân loại mềm" sử dụng chức năng mờ (fuzzy) (Manakos, 2001).

Theo phương pháp phân loại mềm, mỗi lớp của cơ chế phân loại bao gồm các mô tả về lớp đó. Mỗi sự mô tả lớp bao gồm một sự diễn tả mờ cho phép đánh giá các đặc trưng đặc biệt và các toán tử logic của chúng. Một quy tắc mờ có thể có một điều kiện hoặc bao gồm sự kết hợp của vài điều kiện để thõa mãn các yêu cầu đối với một đối tượng được gán vào một lớp. Tập hợp mờ được định nghĩa bởi chức năng các thành viên nhằm xác định các giá trị của các đặc trưng liên quan đến sự điển hình, ít điển hình, không điển hình của một lớp, ví dụ chúng có cao, thấp hoặc 0 thành viên trong tập hợp mờ (Mitri và Gitas, 2002).

Tất cả năm lớp phủ bề mặt trong vùng nghiên cứu được xác định dựa vào cấu trúc hình thành của thực vật, đặc tính của nước và các vật liệu nhân tạo bao gồm: sông, ao hồ, đất canh tác, đất trống và khu công nghiệp. Các quy tắc phân lớp đối với các đối tượng được phát triển sử dụng dấu hiệu phổ, hình dạng, vị trí và các mối quan hệ cấu trúc của các đối tượng. Các quy tắc đó được sử dụng để phân loại cơ bản ảnh dựa vào giá trị phản xạ phổ của lớp phủ bề mặt trên các kênh phổ và chỉ số NDVI (Hình 3, 4).

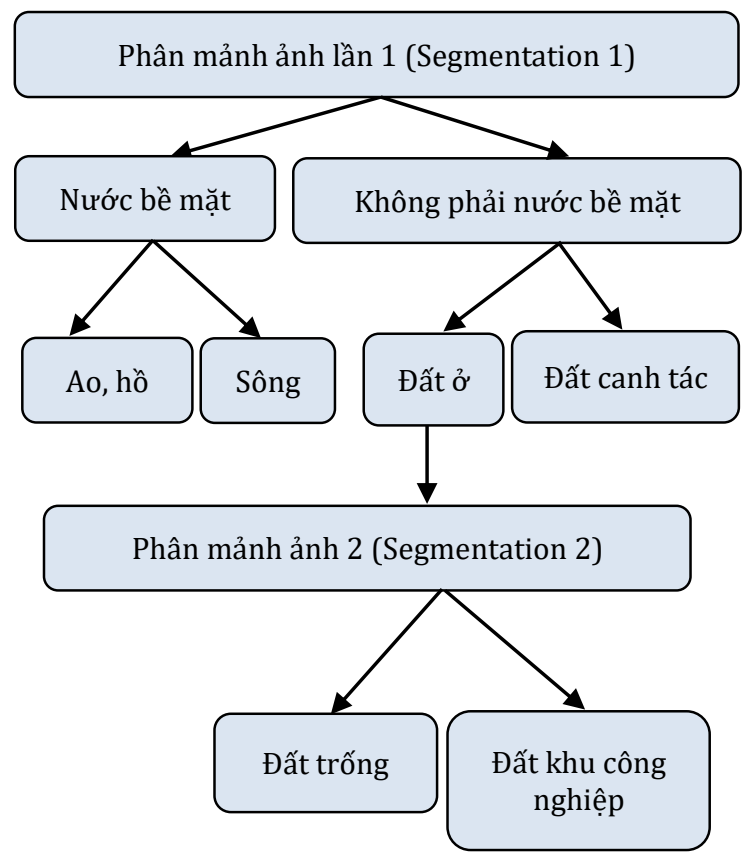

Hình 3. Thiết lập qui tắc cho phân loại.

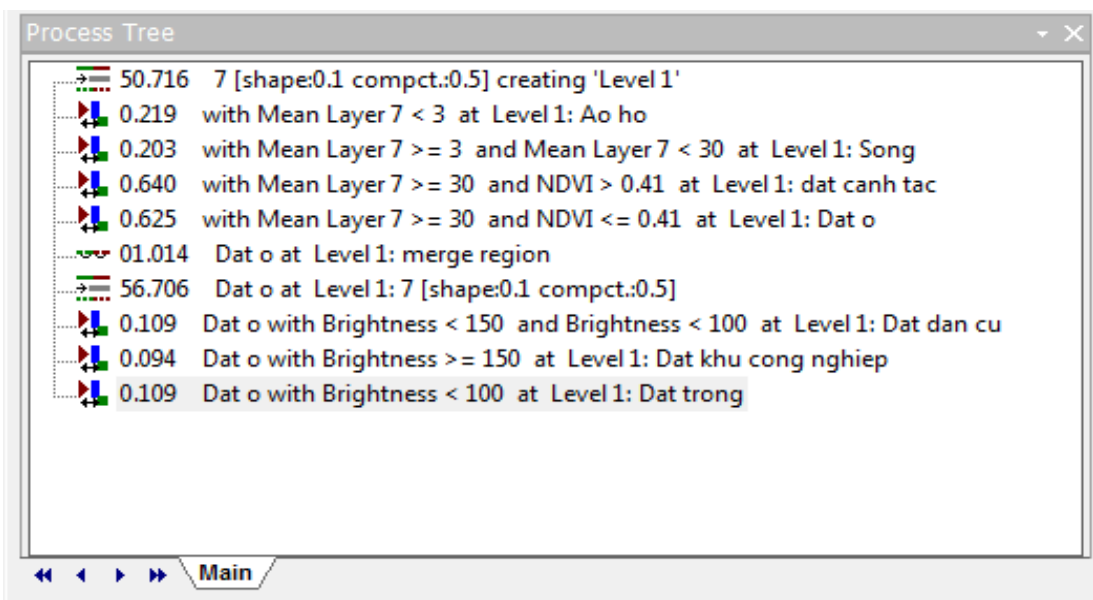

Hình 4. Các bước xây dựng bộ qui tắc cho phân loại ảnh. 
Các mẫu đối với mỗi lớp được lựa chọn từ các đối tượng ảnh như các vùng mẫu trong quá trình phân loại. Các đối tượng được gán theo quy tắc phân loại sử dụng dấu hiệu phổ, hình dạng, vị trí và các mối quan hệ cấu trúc. Các quy tắc này được sử dụng như đối với phân loại mờ với sự gán lớp xác xuất nhất tới mỗi đối tượng.

Bộ nguyên tắc sử dụng trong phân loại đối tượng bao gồm các thuật toán phân mảnh ảnh (segment), các thuật toán phân loại đối tượng ảnh, cũng như các thuật toán kiểm tra thông tin đối tượng ảnh, nhập dữ liệu, xuất dữ liệu được thiết lập trên cửa sổ quá trình cây quyết định.

Việc lập một bộ qui tắc trong phân loại ảnh đối tượng đòi hỏi người phân tích ảnh phải có rất nhiều hiểu biết khác nhau như: đặc trưng của từng kênh ảnh, đặc trưng phản xạ của đối tượng trên ảnh, hiểu biết khu vực nghiên cứu, mối quan hệ giữa các đối tượng với nhau.

\subsection{3. Đánh giá độ chính xác kết quả phân loại}

Phân loại lớp phủ/sử dụng đất từ tư liệu viễn thám và GIS hàm chứa nhiều nguồn thồng tin không chắc chắn bởi vì sự tích lũy và sự lan truyền từ việc lấy mẫu, thu thập, xử lý, phân tích hình ảnh và dữ liệu mặt đất, mô hình hóa, sự biến đổi trong không gian của các biến thể và sự tương tác giữa chúng. Độ chính xác là thông số chỉ mức độ tin cậy của kết quả phân loại đó. Theo Congalton (2008), dựa vào ma trận lẫn đã tính toán được ba độ chính xác là: độ chính xác toàn cảnh (overral accuracy), độ chính xác sản phẩm (producer's accuracy) và độ chính xác sử dụng (user's accuracy) (Congalton và Green, 2008).

\section{Kết quả và thảo luận}

\section{1. Độ chính xác kết quả phân loại}

Để đánh giá độ chính xác phân loại kết quả đạt được, nghiên cứu này đã tiến hành so sánh các điểm dữ liệu mẫu với các lớp hình ảnh được phân loại, điểm được lấy mẫu được phân bố đều trên toàn cảnh, tập trung vào các loại lớp phủ điển hình trong khu vực. Mức độ trùng khớp của ảnh được phân loại và điểm dữ liệu mẫu cung cấp độ chính xác phân loại của quá trình phân loại ảnh. Độ chính xác của kết quả phân loại dựa trên 50 điểm, xấp xỉ 1300 pixel được lấy từ ảnh Google Earth năm 2018. Hệ số Kappa được tính theo công thức của Congalton (Kamal và nnk, 2015), độ chính xác phân loại đạt được thông qua chỉ số Kappa là 0,81 như Bảng 2.

Bảng 2. Đánh giá độ chính xác kết quả phân loại hướng đối tượng trên ảnh Worldview-2.

\begin{tabular}{|c|c|c|c|c|c|c|c|}
\hline Các mẫu & Ao hồ & Sông & $\begin{array}{c}\text { Đất } \\
\text { trống }\end{array}$ & $\begin{array}{c}\text { Đất } \\
\text { canh } \\
\text { tác }\end{array}$ & $\begin{array}{c}\text { Khu } \\
\text { công } \\
\text { nghiệp }\end{array}$ & $\begin{array}{c}\text { Tổng } \\
\text { hàng }\end{array}$ & $\begin{array}{c}\text { Độn } \\
\text { chính } \\
\text { xác sản } \\
\text { xuất }\end{array}$ \\
\hline Ao hồ & 173 & 8 & 0 & 4 & 6 & 191 & 0,91 \\
\hline Sông & 10 & 232 & 15 & 6 & 19 & 282 & 0,82 \\
\hline Đất trống & 7 & 30 & 207 & 12 & 30 & 286 & 0,72 \\
\hline $\begin{array}{c}\text { Đất canh } \\
\text { tác }\end{array}$ & 3 & 8 & 43 & 253 & 25 & 332 & 0,78 \\
\hline $\begin{array}{c}\text { Đất khu } \\
\text { công } \\
\text { nghiệp }\end{array}$ & 4 & 5 & 9 & 20 & 190 & 228 & 0,83 \\
\hline Tổng cột & 197 & 283 & 274 & 295 & 270 & 1319 & \\
\hline $\begin{array}{c}\text { Độ chính } \\
\text { xác người } \\
\text { dùng }\end{array}$ & 0,89 & 0,85 & 0,76 & 0,86 & 0,75 & & \\
\hline $\begin{array}{c}\text { Độ chính } \\
\text { xác toàn bộ }\end{array}$ & \multicolumn{7}{|c|}{0,85} \\
\hline $\begin{array}{c}\text { Chỉ số } \\
\text { Kappa }\end{array}$ & \multicolumn{7}{|c|}{0,81} \\
\hline
\end{tabular}

4.2. Kết quả thực nghiệm của quá trình phân loại ånh vệ tinh Worldview-2

Đầu tiên, để phân biệt nước mặt và không phải nước mặt (đất, thực vật, lớp phủ nhân tạo) cần sử dụng kênh 7 vì bề mặt nước phản xạ phổ rất thấp so với các lớp phủ khác (Hình 5 ). Phần lớp phủ không phải nước sẽ được phân loại thành lớp đất ở và đất canh tác nhờ sự phân biệt tốt nhất giữa thực phủ và đất thể hiện rõ ở kênh 7 của dữ liệu Worldview-2 (Hình 5). Chính vì vậy, trong thiết lập qui tắc phân loại để tách đất canh tác và đất ở có sử dụng các giá trị ngưỡng đối với kênh 7 (Hình 5). Đất ở tiếp tục được tách thành đất trống và khu công nghiệp do sự phản xạ rất mạnh ở bước sóng ngắn đối với kênh 3 cho lớp bề mặt mái nhà ở khu công nghiệp so với phản xạ thấp đối với bề mặt đất trống. Do vậy, giá trị độ sáng (Brightness) được sử dụng để tách hai loại hình lớp phủ bề mặt này trên ảnh vệ tinh theo qui tắc như trong Hình 4.

Kết quả phân loại lớp phủ/sử dụng đất ở Hình 6 cho thấy, khu công nghiệp được bao quanh bởi đất canh tác. Tuy nhiên, trong khu công nghiệp có cả đất trống, đất canh tác và ao hồ nhỏ và có những 


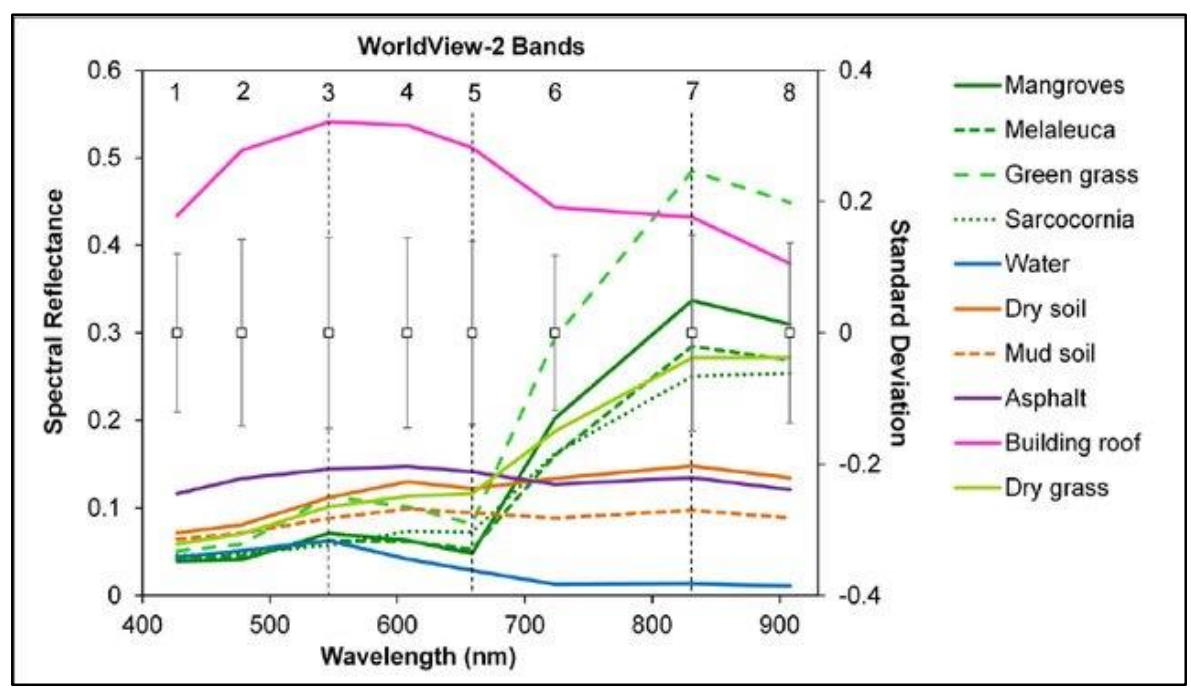

Hình 5. Phản xạ phổ của các đối tượng bề mặt tù̀ các kênh phổ của dũ liệu Worldview-2 (Kamal và nnk., 2015).

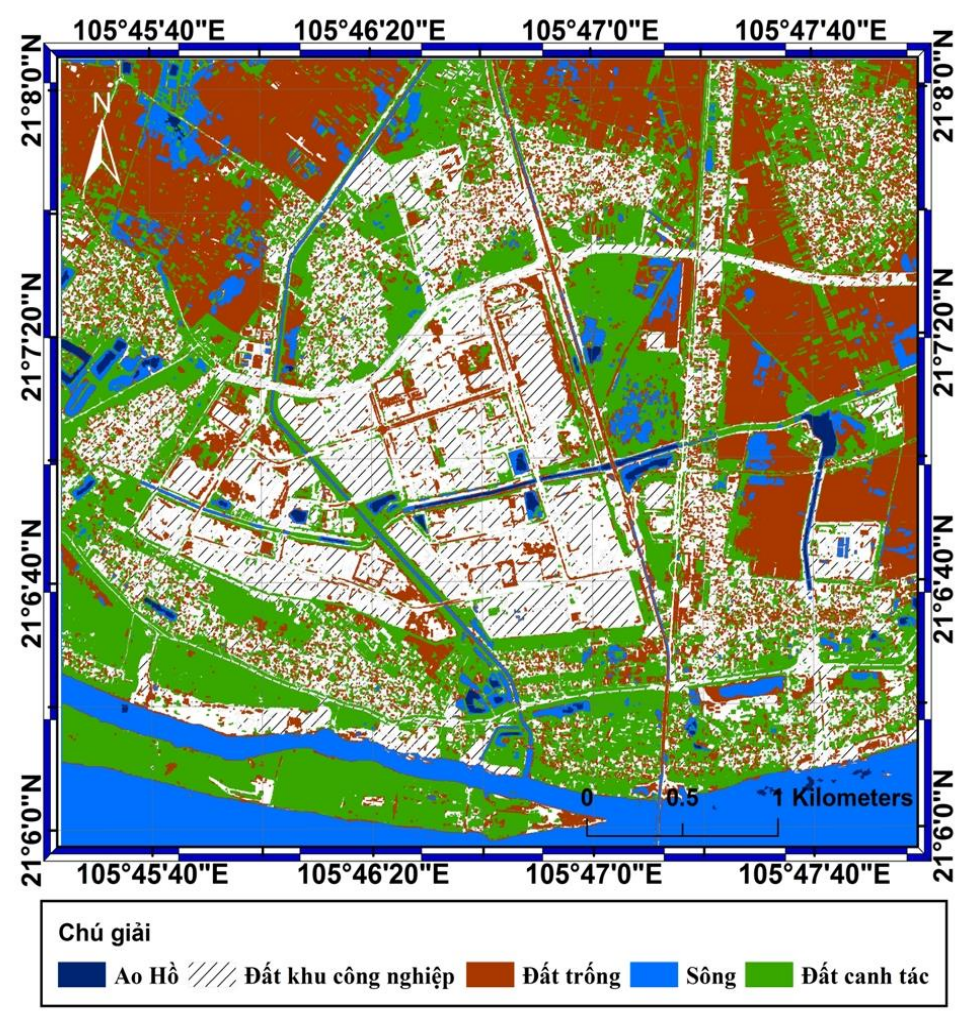

Hình 6. Kết quả phân loại lớp phủ/sử dụng đất khu công nghiệp Bắc Thăng Long.

khu vực trồng cỏ, cây cảnh, hệ thống thoát nước mặt và hệ thống đường giao thông cục bộ phục vụ cho khu công nghiệp. Lớp đất trống tập trung ở phía tây bắc và phía đông bắc của khu vực nghiên cứu. Các khu vực này trước đây là khu vực đất canh tác, nhưng đang chuyển đổi thành đất qui hoạch cho các dự án phát triển mở rộng khu vực đô thị mới có nền đất được san lấp. Các khu dân cư có sự trộn lẫn giữa đất canh tác và đất trống xen giữa khu vực đất trống, đất canh tác và đất khu công nghiệp có diện tích bao phủ rộng hơn. Phía nam của khu vực là sông Hồng với các hệ thống tưới nước phục vụ cho canh tác cây nông nghiệp của người dân sinh sống và trồng trọt. 


\subsection{Thảo luận về độ chính xác kết quả phân loại ảnh vệ tinh Worldview-2}

Kết quả phân loại ảnh vệ tinh và độ chính xác được trình bày trong Hình 6 và Bảng 2 cho thấy, lớp phủ nước mặt sông và ao hồ có độ chính xác cao lần lượt là 0,91 và 0,82 do diện tích nước mặt có độ đồng nhất về phản xạ phổ cao hơn so với các lớp phủ khác. Độ chính xác phân loại đối với lớp phủ đất canh tác và đất trống thấp hơn lần lượt là 0,78 và 0,72 do hai loại hình lớp phủ này có sự trộn lẫn giữa thực vật và đất trống ở ngoài thực địa. Mặc dù đất khu công nghiệp có độ chính xác sản xuất cao $(0,83)$, nhưng độ chính xác người dùng thấp $(0,75)$ do có sự phân loại lẫn các lớp phủ khác sang đất khu công nghiệp thể hiện đối với các pixel lẫn ở cột trong Bảng 2.

\section{Kết luận}

Nghiên cứu này đã thử nghiệm phương pháp phân loại hướng đối tượng đối với ảnh vệ tinh Worldview-2 có độ phân giải không gian cao (kích thước pixel 1,8 m) để chiết tách các đối tượng lớp phủ nhân tạo (đất khu công nghiệp) dựa vào sự khác biệt về phản xạ phổ của các đối tượng lớp phủ tự nhiên, nhân tạo và chỉ số thực vật NDVI tính toán từ 8 kênh phồ.

Sự phân biệt tốt nhất của các đối tượng lớp phủ bề mặt/sử dụng đất dựa vào kênh 3 có phản xạ phổ ở khu công nghiệp mạnh hơn ở các lớp phủ bề mặt khác. Bên cạnh đó khả năng phân biệt tốt lớp thực phủ ở vùng đất canh tác và đất trống, đường nhựa dựa vào kênh 7 rất rõ rệt. Hơn nữa, chỉ số thực vật NDVI cũng cung cấp mật độ thực phủ dày hoặc thưa phục vụ tốt hơn cho công tác phân loại hướng đối tượng.

Kết quả phân loại ảnh thu được diện tích các loại hình lớp phủ/sử dụng đất với độ chính xác toàn bộ $(0,85)$ và chỉ số Kappa $(0,81)$ cho thấy khả năng của việc áp dụng phương pháp phân loại hợp lý đối với khu vực có cả đối tượng lớp phủ tự nhiên và nhân tạo.

\section{Đóng góp của các tác giả}

Lê Thị Thu Hà - lập dàn ý và lên các ý tưởng cơ bản cho bài báo. Viết tổng quan về vấn đề nghiên cứu, tổng hợp, phân tích kết quả thực nghiệm, viết thảo luận vấn đề nghiên cứu đạt được; Nguyễn Hoàng Long - thu thập các loại dữ liệu ảnh vệ tinh cho khu vực thực nghiệm; Nguyễn
Văn Trung - nghiên cứu đặc điểm khu vực thực nghiệm, nghiên cứu đặc điểm các dữ liệu sử dụng, thống kê các thông số cần thiết phục vụ việc giải đoán ảnh vệ tinh, đi thực địa và đánh giá độ chính xác kết quả phân loại trên ảnh vệ tinh.

\section{Tài liệu tham khảo}

Aatz, M., Benz, U., Dehghani, S., Heynen, M., Höltje, A., Hofmann, P., Lingenfelder, I., Mimler, M., Sohlbach, M., Weber, M., \& Willhauck, G. (2004), eCognition Professional: User guide 4.; Munich: Definiens-Imaging.

Belward, A. S., Skøien, J. O. (2015). Who launched what, when and why; trends in global landcover observation capacity from civilian earth observation satellites, ISPRS J. Photogram. Remote Sens., 103, 115-128,

Choodarathnakara, A.L., Ashok, K.T., Shivaprakash, K Dr., and Patil Dr. C. G. (2012). Soft Classification Techniques for RS Data, IJCSET, 2(11), 1468 - 1471.

Congalton, R. G., and Green, K. (2008). Assessing the accuracy of remotely sensed data: Principies and practices. New York. Taylor\& Francis Group.

Desheng Liu and Fanxia. (2010). Assessing objectbased classification: advantages and limitations. Remote Sensing Letters, ISSN: 2150-704X (Print) 2150-7058 (Online).

Digitalglobal. (2009). WorldView-2 Satellite Sensor.

Guo, Q., Kelly, M., Gong, P. and Liu, D. (2007). An object-based classification approach in mapping tree mortality using high spatial resolution imagery. GIScience \& Remote Sensing, 44, 24-47.

Kamal, M., Phinn, S., Johansen, K. (2015). ObjectBased Approach for Multi-Scale Mangrove Composition Mapping Using Multi-Resolution Image Datasets. Remote Sens, 7, 4753-4783.

Kavzoglu, T., Yildiz, M. (2014). Parameter-Based Performance Analysis of Object-Based Image Analysis Using Aerial and Quikbird-2 Images. ISPRS Annals of Photogrammetry, Remote Sensing and Spatial Information Sciences, Vol. II-7, 31-37. 
Manakos, I. (2001). eCognition and Precision Farming. http://www.lrz-muenchen.de/ lnn /. eCognition Application Notes, 2(2), April 2001.

Mario, C. (2009). ESA Advanced Training Course on Land Remote Sensing: Image Classification, ESA

Mitri, G. H., \& Gitas, I. Z. (2002). The development of an object-oriented classification model for operational burned area mapping on the Mediterranean island of Thasos using LANDSAT TM images. Forest Fire Research \& Wildland Fire Safety, Viegas (ed.) Millpress, Rotterdam, ISBN 90-77017-72-0.

Qihao Weng. (2020). Techniques and Methods in
Urban Remote Sensing, IEEE Press Wiley, Printed in the United States of America.

Whiteside, T., \& Ahmad, W. (2004). Objectoriented classification of ASTER imagery for landcover mapping in monsoonal northern Australia. Proceedings of 12th Australasian Remote Sensing and Photogrammetry Conference.

Willhauck, G., Schneider, T., De Kok, R., \& Ammer, U. (2000). Comparison of object-oriented classification techniques and standard image analysis for the use of change detection betweeen SPOT multispectral satellite images and aerial photos. Proceedings of XIX ISPRS Congress, 16-22 July, Amsterdam. 